\title{
Sikap Petani Terhadap Program Gelar Lapang Inovasi Pertanian (Glip) Berbasis Padi di Kecamatan Guluk-Guluk, Kabupaten Sumenep
}

\section{The Attitudes of Farmers Toward Agricultural Innovation Field Organizing Program Based on Paddy in Guluk-Guluk Sub-District ff Sumenep Regency}

\author{
Sonia Aprilia Susanta, Agung Wibowo, Emi Widiyanti \\ Program Studi Penyuluhan dan Komunikasi Pertanian Fakultas Pertanian \\ Universitas Sebelas Maret \\ J1.Ir.Sutami No.36 A Kentingan Surakarta 57126 Telp./Fax (0271) 637457 \\ Email: Soniaaprilia@student.uns.ac.id
}

\begin{abstract}
Abstrak: This research was aimed to investigate the attitudes of farmers toward Agricultural Innovation Field Organizing Program Based on Paddy, to study farmer's attitude toward program, to study the factors that form the attitude of farmers toward the program, and analyzing the relationship between factors influencing farmer's attitude toward program. The basic method was quantitative research with survey technique. Location of research was determined purposivelywhere is District Guluk-Guluk Sumenep Regency. The sample was determined by random sampling technique, who are 43 rice farmers participated in the Agricultural Innovation Field Organizing Program Based on Paddy for the August-November period. In determining respondent's number from each farmer group, it used proportional random sampling. The data used that for analysiswere primary data and secondary data. Data was analyzed by Rank Spearman correlation coefficient (rs) to know the relation of factors that formed attitude with farmer's attitude toward Agricultural Innovation Field Organizing Program Based on Paddy. The factors that formed the farmers 'attitude in Guluk-Guluk Sub-district of Sumenep Regency were personal experience in very high category, non-formal education in very high category, cultural role in high category, the role of others that are considered important in medium category, media exposure in low category, and extension roles in very high categories.Based on rank spearman $(r)$, showed thatthere was a significant relationship between personal experience, non-formal education, the role of culture, and the role of investigator with farmer's attitudes toward the program, while the roles of others that were considered important and mass media exposure had no significant relationship with farmers'attitudes toward the program
\end{abstract}

Keywords: Attitude, Farmers, Agricultural Innovation Field Organizing Program Based on Paddy, Rank Spearman

\begin{abstract}
Abstrak: Penelitian ini bertujuan mengkaji sikap petani terhadap Program Gelar Lapang Inovasi Pertanian (GLIP) Berbasis Padi, mengkaji sikap petani terhadap program, mengkaji faktor-faktor pembentuk sikap petani terhadap program, dan menganalisis hubungan antara faktor-faktor yang mempengaruhi sikap petani terhadap program. Metode dasar yang digunakan adalah penelitian kuantitatif dengan teknik survei. Lokasi penelitian ditentukan secara purposive yaitu Kecamatan Guluk-Guluk Kabupaten Sumenep. Sampel ditentukan dengan teknik random sampling,sebanyak 43 petani padi yang mengikuti Program GLIP Berbasis Padi Periode Bulan Agustus-November. Penentuan jumlah responden dari masing-masing kelompok tani menggunakan proportional random sampling. Data yang digunakan untuk analisis adalah data primer dan data sekunder. Data di analisis menggunakan koefisien korelasi Rank Spearman (rs) untuk mengetahui hubungan faktor-faktor pembentuk sikap dengan sikap petani terhadap Program GLIP Berbasis Padi. Faktor-faktor pembentuk sikap petani di Kecamatan Guluk-Guluk Kabupaten Sumenep yaitu pengalaman pribadi dalam kategori sangat tinggi, pendidikan non formal dalam kategori sangat tinggi, peran kebudayaan dalam kategori tinggi, peran orang lain yang dianggap penting dalam kategori sedang, terpaan media massa dalam kategori rendah, dan peran penyuluh dalam kategori sangat tinggi.Berdasarkan uji rank spearman $\left(\mathrm{r}_{\mathrm{s}}\right)$ menunjukkan bahwa terdapat hubungan yang signifikan antara pengalaman pribadi, pendidikan non formal, peran kebudayaan, dan peran penyuluh dengan sikap petani terhadap program, sedangkan peran orang lain yang dianggap penting dan terpaan media massa tidak terdapat hubungan yang signifikan dengan sikap petani terhadap program.
\end{abstract}

Kata Kunci: Petani, Program GLIP Berbasis Padi, Rank Spearman, Sikap 


\section{PENDAHULUAN}

Swasembada pangan merupakan suatu keadaan dimana sebuah negara mampu memenuhi kebutuhannya sendiri dalam bidang pangan.Berdasarkan Peraturan Menteri Pertanian Republik Indonesia nomor 131/permentan/ ot.140/12/2014bahwa pemerintah menetapkan target produksi pangan strategis nasional dalam rangka mewujudkan ketahanan pangan nasional, yang meliputi 7 (tujuh) komoditas pangan utama, yaitu: padi, jagung, kedelai, tebu/gula pasir, daging sapi, aneka cabai dan bawang merah. Kementerian Pertanian bersama-sama dengan kementerian/lembaga non kementerian lainnya, pemerintah daerah dan para pelaku usaha pertanian guna mencapai target produksi pangan strategis nasional.

Jawa Timur merupakan salah satu provinsi yang menjalankan program ketahanan pangan yang sekaligus sebagai penghasil utama tanaman padi. Provinsi Jawa Timur memberikan kontribusi terhadap produksi beras nasional $\pm 20 \%$. Dukungan Jawa Timur dalam pencapaian target tersebut pada tahun 2016 diharapkan dapat memproduksi padi 12.692.802 ton dari luas tanam 2.181.474 $\mathrm{Ha}$ atau luas panen 2.108.519 $\mathrm{Ha}$ dengan produktivitas $60,20 \mathrm{ku} / \mathrm{Ha}$. Namun demikian hampir seluruh kabupaten di Jawa Timur masih terdapat desa rawan pangan. Hal ini dikarenakan adanya keragaman tingkat produktivitas padi antar lokasi, yang merupakan akibat dari keragaman kesuburan tanah, penerapan teknologi produksi, ketersediaan air irigasi dan kondisi sosial ekonomi petani, khususnya kelembagaan agribisnis yang belum berkembang diberbagai daerah (Kementan, 2015).

Gelar Lapang Inovasi Pertanian (GLIP) Berbasis Padi merupakan program lapang baru yang direalisasikan oleh Balai Pengkajian Teknologi Pertanian (BPTP) Jawa Timur, sebagai bentuk dukungan dalam rangka swasembada hasil pertanian khususnya tanaman padi. Program ini dilakukan untuk memberikan gambaran mengenai pentingnya pembangunan dan pengembangan sub sistem hulu sampai dengan hilir berbasis kawasan dan inovasi teknologi padi. Program ini sudah terlaksana sebanyak 3 kali masa tanam dalam kurun waktu 2 tahun terakhir. Program ini memiliki karakteristik inovasi yang meliputi keunggulan relatif (relative advantage), kesesuaian (compatibility), kemampuan diuji cobakan (trialability), dan kemampuan diamati (observability). Program inimendukung tahapan adopsi inovasi pada tahap pertama yaitu awareness. Hal ini dikarenakan program ini bertujuan untuk memperkenalkan beberapa inovasi baru kepada petani yang meliputi, 7 Varietas Unggul Baru (VUB) padi tahan terhadap kondisi minim ketersediaan air atau kekeringan, sistem jajar legowo, pemanfaatan jerami untuk pakan ternak dan pupuk organik, serta peningkatan indeks penanaman.

Dari uraian diatas, perlu dilakukan penelitian mengenai pemahaman sikap petani terhadap Program Gelar Lapan Inovasi Pertanian (GLIP) Berbasis Padi. Hal ini didasarkan pada pemikiran bahwa Program Gelar Lapan Inovasi Pertanian (GLIP) Berbasis Padi diharapkan mampu mendukung sikap positif petani terhadap komponen teknologi pada program. Sikap positf tersebut idealnya akan meningkatkan minat petani untuk menerapkan teknologi-teknologi yang ditawarkan tersebut.Dengan demikian, apabila dikaitkan dengan pemahaman mengenai sikap petani terhadap Program Gelar Lapan Inovasi Pertanian (GLIP) Berbasis Padi, akan diperoleh pemikiran mengenai kecenderungan petani untuk bertidak, yaitu menerapkan komponen teknologi yang ada. Berdasarkanuraianlatar belakang diatas, maka penelitian ini dilakukandengantujuan, mengkaji sikap petani terhadap Program GLIP BerbasisPadi di Kecamatan Guluk-Guluk, Kabupaten Sumenep; mengkaji faktor-faktor pembentuk sikap petani terhadap Program GLIP BerbasisPadi di Kecamatan Guluk-Guluk, Kabupaten Sumenep; menganalisis hubungan antara faktor-faktor yang mempengaruhi sikap petani terhadap Program GLIP BerbasisPadi di Kecamatan Guluk-Guluk, Kabupaten Sumenep.

\section{METODE PENELITIAN}

Metode dasar penelitian yang
digunakan dalam penelitian ini adalah
metodekuantitatifdenganmenggunakan teknik
survei, yaitu pengamatan atau penyelidikan
yang kritis untuk mendapatkan keterangan yang
sebenarnya dan baik terhadap suatu persoalan
tertentu dan di dalam suatu daerah. Penentuan


lokasi penelitian dilakukan secara sengaja (purposive sampling) yaitu di Kecamatan GulukGuluk, Kabupaten Sumenep. Populasi dalam penelitian adalah petani padi yang mengikuti Program GLIP Berbasis Padi di Kecamatan Guluk-Guluk, Kabupaten Sumenep periode bulan Agustus-November dengan total populasi 143 orang.

Tabel 1. Jumlah Anggota Kelompok Tani yang Terlibat dalam Program GLIP Berbasis Padi Tahun 2017

\begin{tabular}{lllr}
\hline No & Desa & Kelompok Tani & $\begin{array}{r}\text { Jumlah } \\
\text { Anggota }\end{array}$ \\
\hline 1 & Bragung & KWT Kasih Ibu & 40 \\
2 & Bragung & KWT Al-bannah & 30 \\
3 & Bragung & Al Irsyad & 41 \\
4 & Guluk-Guluk & Sumber Hasil & 32 \\
& Total & & 143 \\
\hline
\end{tabular}

Sumber: Data Sekunder

Penentuan sampel dalam penelitian ini dilakukan dengan menggunakan metode Proportional random sampling yaitu pengambilan sampel dengan menetapkan jumlah tergantung besar kecilnya sub populasi (Sugiyono, 2012 : 8283). jumlah sampel dalam penelitian ini diambil $30 \%$ dari keseluruhan populasi sehingga didapat hasil 42,9 dan dibulatkan menjadi 43 petani.Sumber data dalam penelitian ini yaitu data primer dan data sekunder. Metode analisis data menggunakan rumus lebar interval untuk mengetahui sikap petani terhadap Program GLIP Berbasis Padi, serta menggunakan uji korelasi Rank Spearman $\left(r_{s}\right)$ untuk menguji adanya hubungan antara faktorfaktor pembentuk sikap petani terhadap Program GLIP Berbasis Padi.

\section{HASIL DAN PEMBAHASAN}

Menurut data Kecamatan Guluk-Guluk dalam Angka Tahun 2016, luas wilayah di Kecamatan Guluk-Guluk adalah 6.311,16 Ha yang terdiri dari luas tanah sawah $1.566,73 \mathrm{Ha}$ dan luas tanah kering 4.744,43 Ha. Jumlah penduduk lakilaki dan perempuan di Kecamatan Guluk-Guluk secara berturut-turut sebanyak 23.705 orang dan 25.574 orang. Dengan nilai sex ratio sebesar 92,69. Rata-rata kepadatan geografisnya yaitu setiap 1 $\mathrm{km}^{2}$ ditempati oleh 801 jiwa.

Program GelarLapangInovasiPertanian (GLIP) BerbasisPadi dilakukan untuk memberikan gambaran mengenai pentingnya pembangunan dan pengembangan sub sistem hulu sampai dengan hilir berbasis kawasan dan inovasi teknologi padi. Program inimerupakan salah satu strategi untuk mengkomunikasikan inovasi teknologi pertanian kepada khalayak/pelaku utama/petani dan stakeholder lainnya, supaya terjadi percepatan hilirisasi penerapan inovasi.Program ini memiliki 2 tujuan, yaitu tujuan jangka panjang dan jangka pendek. Tujuan jangka panjang yang akan dicapai dari program ini adalah membangun model kawasan agribisnis berbasis inovasi teknologi padi, sedangkan tujuan jangka pendeknya pada tahun 2016 diantaranya, meningkatkan Indek Pertanaman, menerapkan sistem tanam jajar legowo 2:1, merkenalan 7 VUB, dan melaksanakan pemanfaatan jerami padi untuk pakan ternak dan pupuk organik dalam bentuk Pelatihan.

\section{Sikap Petani terhadap Program Gelar lapang Inovasi Pertanian (GLIP) BerbasisPadi}

Sikap petani terhadap Program GLIP diukur menggunakan skala likert. Sikap yang diukur adalah sikap terhadap tujuan, pelaksanaan, dan manfaat program. Berikut ini adalah tabel distribusi responden berdasakan sikap petani terhadap program. 
Tabel 2. Distribusi Responden Berdasarkan Sikap Petani terhadap Program GLIP BerbasisPadi

\begin{tabular}{|c|c|c|c|c|c|}
\hline \multirow{2}{*}{ No } & \multirow{2}{*}{ Uraian } & \multirow{2}{*}{ Kategori } & \multirow{2}{*}{ Skor } & \multicolumn{2}{|c|}{ Distribusi } \\
\hline & & & & Jumlah & $\%$ \\
\hline \multirow[t]{5}{*}{1} & \multirow[t]{5}{*}{ Tujuan Program } & Sangat Buruk & $6,0-10,7$ & 0 & 0 \\
\hline & & Buruk & $10,8-15,5$ & 0 & 0 \\
\hline & & Cukup & $15,6-20,3$ & 1 & 2,3 \\
\hline & & Baik & $20,4-25,1$ & 6 & 14,0 \\
\hline & & Sangat Baik & $25,2-30,0$ & 36 & 83,7 \\
\hline \multirow[t]{5}{*}{2} & \multirow[t]{5}{*}{ Pelaksanaan Program } & Sangat Buruk & $11,0-19,7$ & 0 & 0 \\
\hline & & Buruk & $19,8-28,5$ & 0 & 0 \\
\hline & & Cukup & $28,6-37,3$ & 1 & 2,3 \\
\hline & & Baik & $37,4-46,1$ & 8 & 18,6 \\
\hline & & Sangat Baik & $46,2-55,0$ & 34 & 79,1 \\
\hline \multirow[t]{5}{*}{3} & \multirow[t]{5}{*}{ Manfaat Program } & Sangat Buruk & $6,0-10,7$ & 0 & 0 \\
\hline & & Buruk & $10,8-15,5$ & 0 & 0 \\
\hline & & Cukup & $15,6-20,3$ & 1 & 2,3 \\
\hline & & Baik & $20,4-25,1$ & 13 & 30,2 \\
\hline & & Sangat Baik & $25,2-30,0$ & 29 & 67,5 \\
\hline \multirow[t]{5}{*}{4} & \multirow{5}{*}{$\begin{array}{l}\text { Sikap Petani terhadap } \\
\text { Program Gelar Lapang } \\
\text { Inovasi Pertanian (GLIP) } \\
\text { Berbasis Padi }\end{array}$} & Sangat Buruk & $23,0-41,3$ & 0 & 0 \\
\hline & & Buruk & $41,4-59,7$ & 0 & 0 \\
\hline & & Cukup & $59,8-78,1$ & 0 & 0 \\
\hline & & Baik & $78,2-96,5$ & 8 & 18,6 \\
\hline & & Sangat Baik & $96,6-115,0$ & 35 & 81,4 \\
\hline
\end{tabular}

Sumber: Analisis Data Primer, 2017

Sikap petani terhadap Program GLIP Berbasis Padi mayoritas (81,4\%) tergolong dalam kategori sangat setuju sebanyak 35 petani. Hasil tersebut menunjukkan bahwa sebagian besar responden sangat setuju dengan tujuan dari Program GLIPBerbasis Padi. Menurut Katz (2010), fungsi sikap salah satunya yaitu fungsi instrumen atau fungsi manfaat. Hal ini berkaitan dengan sarana dan tujuan orang memandang sejauh mana objek sikap dapat digunakan sebagai sarana dalam rangka mencapai tujuan. Bila objek sikap dapat mencapai tujuannya maka seseorang akan bersifat positif terhadap objek tersebut.

Sikap petani terhadap tujuan Program GLIP Berbasis Padi mayoritas (83,7\%) tergolong dalam kategori sangat setuju sebanyak 36 petani. Hal ini dikarenakan Program GLIPBerbasis Padi telah memberikan kesan yang baik bagi petani. Karena sebagian besar responden sangat setuju dengan pelaksanaan atau kegiatan yang diberikan dari program tersebut dan dapat diketahui bahwa program tersebut dilaksanakan kesemua kelompok tani yang menjadi peserta program.

Sikap petani terhadap pelaksanaan Program GLIP Berbasis Padi mayoritas (79,1\%) tergolong dalam kategori sangat setuju sebanyak 34 petani. Hasil tersebut menunjukkan bahwa sebagian besar responden sangat setuju bahwa dengan adanya program ini petani mampu memanfaatkan lahan sub optimal (lahan tadah 
hujan), mampu meningkatkan kuantitas hasil usahatani, mampu meningkatkan kualitas hail usahatani, mengefisienkan biaya usahatani, mampu meningkatkan populasi tanam dengan sistem tanam jajar legowo 2:1, dan menggunakan VUB yang adaptif terhadap iklim ekstrim.

Sikap petani terhadap manfaat Program GLIP Berbasis Padi mayoritas (67,5\%) tergolong dalam kategori sangat setuju sebanyak 29 petani. Hasil tersebut menunjukkan bahwa sebagian besar responden sangat setuju dengan adanya program inibaikdarisegitujuan, pelaksanaan, manfaat.

\section{Faktor-Faktor Pembentuk Sikap}

Faktor-faktor yangsikapadalah faktorfaktor apa saja yang mempengaruhi sikap seseorang meliputi pengalamanpribadi, pendidikan non formal, perankebudayaan, peran orang lain yang dianggappenting, terpaan media massa, danperanpenyuluh. Berikut disajikan Tabel2 yaitu tentangdistribusi responden berdasarkan faktorfaktor pembentuksikap.

Tabel 3. Distribusi Responden Berdasarkan Faktor Pembentuk Sikap

\begin{tabular}{llcccr}
\hline \multirow{2}{*}{ No } & Faktor Pembentuk Persepsi & \multirow{2}{*}{ Kategori } & Skor & \multicolumn{2}{c}{ Distribusi } \\
\cline { 5 - 6 } & & & Jumlah & $\%$ \\
\hline 1 & PengalamanPribadi & Sangat Tinggi & $12,6-15,0$ & 17 & 39,5 \\
2 & Pendidikan Non Formal & Sangat Tinggi & $8,4-10,0$ & 18 & 41,9 \\
3 & Peran Kebudayaan & Tinggi & $13,6-16,7$ & 27 & 62,8 \\
4 & Peran Orang Lain yang Dianggap Penting & Sedang & $13,0-16,0$ & 16 & 37,2 \\
5 & Terpaan Media Massa & Rendah & $5,4-7,7$ & 25 & 58,1 \\
6 & Peran Penyuluh & Sangat Tinggi & $12,6-15,0$ & 25 & 58,1 \\
\hline
\end{tabular}

Sumber: Analisis Data Primer, 2017

Kategori pengalaman pribadi petani tergolong sangat tinggi (39,5\%) sebanyak 17 petani. Hal ini menunjukkan bahwa sebagian besar petani memiliki pengalaman yang baik dalam lamanya berusahatani, lamanya tergabung dalam kelompok tani, dan seberapa sering petani ikutserta dalam program.

Pendidikan nonformal petani tergolong sangat tinggi $(41,9 \%)$ sebanyak 18 petani. Hal ini menunjukkan bahwa sebagian besar petani aktif dalam pendidikan non formal baik kegiatan penyuluhan maupun pelatihan yang berkaitan dengan Program GLIPBerbasis Padi maupun diluar program.

Peran kebudayaan petani sebagian besar termasuk dalam kategori tinggi, dengan prosentase sebesar $62,8 \%$ atau sebanyak 27 petani. Hal ini menunjukkan bahwa sebagian besar responden mulai melakukan dan menerapkan inovasi-inovasi pertanian serta mulai terbuka dengan informasi yang diberikan dari luar desa terkait pertanian.

Kategori peran orang lain yang dianggap penting tergolong sedang (37,2\%) sebanyak 16 petani.Hal ini dapat diartikan bahwa orang lain yang dianggap penting cukup berperan bagi petani. Sebagian besar responden menilai bahwa tokoh masayrakat kurang berperan dalam keikut sertaan petani pada ProgramGLIP Berbasis Padi. Peran orang lain yang dianggap penting ini dapat berupa pemberian saran dan masukan dalam berusahatani

Terpaan media massa sebagian besar termasuk dalam kategori rendah, dengan prosentase sebesar $58,1 \%$ atau sebanyak 25 petani. Hal ini menunjukkan bahwa masih rendahnya aktivitas petani untuk mencari informasi terkait pertanian dari media massa. Kondisi di lapang menjelaskan bahwa masih rendahnya persebaran informasi di media massa terkait program, sehingga petani cukup kesulitan untuk memperoleh informasi selain dari penyuluh BPTP maupun BPP.

Peran penyuluh sebagian besar termasuk dalam kategori sangat tinggi dengan prosentase sebesar $58,1 \%$ atau sebanyak 25 petani. Hal ini dapat diartikan bahwa penyuluh dianggap memiliki peranan penting dalam keberlangsungan berusahatani. Penyuluh berperan dalam menyampaikan setiap informasi. 
Hubungan Faktor-Faktor Pembentuk Sikap dengan Sikap Petaniterhadap Program Gelar Lapang Inovasi Pertanian (GLIP) BerbasisPadi
Berikut hasil analisis hubung anantara faktor pembentuk sikap dengan sikap petani terhadap Program GLIP Berbasis Padi.

Tabel 3. Hubungan Faktor Pembentuk SikapPetani terhadap Program Gelar Lapang Inovasi Pertanian (GLIP) Berbasis Padi

\begin{tabular}{llllllr}
\hline \multirow{2}{*}{ No } & Faktor Pembentuk Persepsi (X) & \multicolumn{3}{c}{ Persepsi Total (Y) } & Keterangan \\
\cline { 3 - 5 } & & $\mathbf{r}_{\mathbf{s}}$ & $\begin{array}{l}\text { Sig. } \\
(\mathbf{2 - t a i l e d})\end{array}$ & $\mathbf{t}_{\text {hitung }}$ & \\
\hline 1. & Pengalaman Pribadi & $0,301^{*}$ & 0,050 & 2,119 & \\
2. & Pendidikan Non Formal & $0,330^{*}$ & 0,030 & 2,371 & & Signifikan \\
3. & Peran Kebudayaan & $0,551^{* *}$ & 0,000 & 5,066 & Signifikan \\
4. & Peran Orang Lain yang Dianggap Penting & 0,039 & 0,802 & 0,249 & Tidak Signifikan \\
5. & Terpaan Media Massa & 0,230 & 0,138 & 1,555 & Tidak Signifikan \\
6. & Peran Penyuluh & $0,301^{*}$ & 0,050 & 2,119 & Signifikan \\
\hline
\end{tabular}

Sumber : Analisis Data Primer, 2017

Keterangan :

$\begin{array}{ll}\mathrm{r}_{\mathrm{s}} & : \text { Korelasi Rank Spearman } \\ \mathrm{t}_{\text {hit }} & : \text { t hitung } \\ \mathrm{t}_{\text {tabel }} & : 2,020(\alpha=0,05) \\ \mathrm{t}_{\text {tabel }} & : 2,701(\alpha=0,01) \\ * & : \text { signifikan pada taraf kepercayaan } \\ & 95 \% \\ * * & : \text { signifikan pada taraf kepercayaan } \\ & 99 \%\end{array}$

Terdapat hubungan yang signifikan antara faktor pengalaman pribadi dengan sikap petani terhadap Program GLIP Berbasis Padi dengan tingkat kepercayaan 95\%.Hasil yang signifikan menunjukkan bahwa semakin tinggi pengalaman pribadi petani dalam berusaha tani dan tergabung dalam kelompok tani maka semakin baik sikap petani terhadap Program GLIP Berbasis Padi. Hasil penelitian sesuai dengan pendapat dari Mahmud (2009), bahwa kebanyakan aktivitas petani seharihari bergantung pada pengalaman yang terdahulu. Pengalaman pribadi yang berkesan dan kuat, dapat menjadi dasar pembentukan sikap. Lamanya pengalaman pribadi seseorang dalam berusaha tani akan mempengaruhi sikap mereka dalam menerima suatu program. Petani menunjukkan sikap yang positif terhadap Program GLIP karena beranggapan bahwa program tersebut memiliki manfaat bagi usahatani mereka, yaitu adanya peningkatan produktivitas baik dari segi kualitas maupun kuantitas.

Terdapat hubungan yang signifikan antara faktor pendidikan non formal dengan sikap petani terhadap Program GLIP Berbasis Padi dengan tingkat kepercayaan 95\%.Hasil yang signifikan menunjukkan bahwa semakin tinggi keterlibatan petani dalam kegiatan penyuluhan dan pelatihan yang diberikan oleh penyuluh maka semakin baik pula sikap petani terhadap Program GLIP Berbasis Padi. Hasil penelitian ini sesuai dengan pendapat dari Azwar (2013 : 35-36) bahwa kegiatan penyuluhan merupakan sistem pendidikan non formal berupaya yang untuk mengubah perilaku sasaran agar memiliki pengetahuan pertanian dan berusahatani. Pendidikan non formal merupakan salah satu faktor pembentuk sikap

Terdapat hubungan yang signifikan antara faktor peran kebudayaan dengan sikap petani terhadap Program GLIP Berbasis Padi dengan tingkat kepercayaan 99\%.Hal ini menunjukkan bahwa semakin tinggi tingkat peran kebudayaan yang diikuti oleh petani maka sikap petani juga semakin baik terhadap Program GLIP Berbasis Padi.Sesuai dengan pendapat dari Azwar (2013: 33-34), bahwa kebudayaan tanpa kita sadari telah mewarnai sikap anggota masyarakatnya karena kebudayaan yang memberikan corak pengalaman 
individu-individu yang menjadi anggota kelompok masyarakat asuhannya. Kebudayaan pulalah yang telah menanamkan garis pengarah sikap kita terhadap berbagai masalah maupun terhadap suatu objek psikologi. Kondisi dilapangan pada penelitian ini menunjukkan bahwa peran kebudayaan berkaitan dengan keterbukaan responden terhadap inovasi baru yang datang dari luar desa. Mayoritas peserta program melakukan dan menerapkan inovasi-inovasi dalam kegiatan berusahataninya.

Tidak terdapat hubungan yang signifikan antara faktor peran orang lain yang dianggap penting dengansikap petani terhadap Program GLIP Berbasis Padi dengan tingkat kepercayaan 95\%. Hasil yang tidak signifikan antara peran orang lain yang dianggap penting terhadap program dikarenakan pendapat dari orang lain tetap didengar tetapi untuk pengambilan keputusannya terkait sikaptetap dari diri sendiri. Berbeda dengan pendapat dari Azwar (2013 : 3233 ), yang menyatakan bahwa peran orang lain yang dianggap penting merupakan salah satu komponen sosial yang dapat membentuk sikap seseorang. Begitupula dengan pendapat dari Zuchdi (1995 : 51-63), yang menyatakan bahwa manusia cenderung bersikap sama dengan sikap orang-orang yang kita anggap penting bagi diri kita.

Tidak terdapat hubungan yang signifikan antara faktor terpaan media massa dengan sikap petani terhadap Program GLIP Berbasis Padi dengan tingkat kepercayaan 95\%. Hasil yang tidak signifikan antara terpaan media massa terhadap Program GLIP Berbasis Padi berarti sering tidaknya responden dalam mengakses internet, penggunaan media elektronik, dan media cetak untuk mencari informasi pertanian khususnya terkait program tidak ada hubungannya dengan sikap mereka terhadap program.Berbeda dengan pendapat dari Walgito (1990 : 113), yang menyatakan bahwa komunikasi memiliki peranan penting sebagai faktor pembentuk sikap. Kondisi yang ada di lapang adalah adanya keterbatasan untuk mengakses media cetak yang beredar di Kecamatan Guluk-Guluk untuk koran dan majalah masih sangat rendah dikarenakan pemahaman terhadap Bahasa Indonesia masih kurang, meskipun mengerti tetapi sebagian petani kurang memahami secara jelas karena bahasa yang sering digunakan adalah Bahasa Madura.
Keterbatasan mengakses media cetak dikarenakan responden hanya memperoleh dari penyuluh saat kegiatan penyuluhan saja.Sulitnya sinyal radio dan keterbatasan akses internet dari segi sinyal maupun kepemilikan smart phone.

Terdapat hubungan yang signifikan antara faktor peran penyuluh dengan sikap petani terhadap Program GLIP Berbasis Padi dengan tingkatkepercayaan 95\%.Hasil yang signifikan menunjukkanbahwasemakin tinggiperan penyuluh maka semakin baiksikap petani terhadap Program GLIP Berbasis Padi. Hasil penelitian ini sesuai dengan pendapat dari Suhardiyanto (1992), yang menyatakan bahwa seorang penyuluh membantu para petani dalam usaha mereka meningkatkan produksi dan mutu hasil produksinya untuk meningkatkan kesejahteraan.Kondisi dilapangan pada penelitian ini menunjukkan bahwa penyuluh menjalankan perannya sebagai mediator, pendidik, fasilitator serta motivator dengan baik. Penyuluh mampu menjelaskan informasi program yang ada terutama terkait dengan GLIP. Selain itu penyuluh juga menampung permasalahan yang dialami oleh petani untuk kemudian disampaikan kepada pihak dinas pertanian. Sehingga permasalah petani dapat segera diatasi dan

dicari solusinya. Sebagai seorang pendidik penyuluh juga memberikan pengetahuannya terkait dengan Program GLIP sehingga petani paham dan mampu melaksanakan program tersebut. Semakin tinggi peran penyuluh maka semakin positif sikap petani terhadap suatu program, begitupula sebaliknya. Peran penyuluh dinilai penting dalam keberlangsungan Program GLIP BerbasisPadi dikarenakan informasi yang diperoleh petani bersumber dari penyuluh khususnya terkait program.

\section{KESIMPULAN DAN SARAN}

\section{Kesimpulan}

Berdasarkan hasil penelitian dan pembahasan yang mengkaji hubungan faktorfaktor pembentuk sikap dengan sikap petani terhadap Program Gelar Lapang Inovasi Pertanian (GLIP) Berbasis Padi, kesimpulan yang dapat diambil adalah: 
Sikap petani terhadap Program Gelar Lapang Inovasi Pertanian (GLIP) Berbasis Padi di Kecamatan Guluk-Guluk, Kabupaten Sumenep mayoritas dalam kategori sangat baik dengan rincian : sikap petani terhadap tujuan Program GLIP Berbasis Padi mayoritas termasuk dalam kategori sangat baik, sikap petani terhadap pelaksanaan Program GLIP Berbasis Padi mayoritas termasuk dalam kategori sangat baik, dan sikap petani terhadap manfaat Program GLIP Berbasis Padi mayoritas termasuk dalam kategori sangat baik.

Faktor-faktor pembentuk sikap petani terhadap Program GLIP Berbasis Padi di Kecamatan Guluk-Guluk, Kabupaten Sumenep yaitu pengalaman pribadi mayoritas dalam kategori sangat tinggi, pendidikan non formal mayoritas dalam kategori sangat tinggi, peran kebudayaan mayoritas dalam kategori tinggi, peran orang lain yang dianggap penting mayoritas dalam kategori sedang,terpaan media massamayoritas dalam kategori rendah, dan peran penyuluh mayoritas dalam kategori sangat tinggi.

Hubungan antara faktor-faktor pembentuk sikap terhadap sikap petani terhadap Program GLIP Berbasis Padiyaitu: terdapat hubungan yang signifikan antara pengalaman pribadi, pendidikan non formal, peran kebudayaan, dan peran penyuluh dengan sikap petani terhadap Program GLIP Berbasis Padi. Sedangkanperan orang lain yang dianggap pentingdan terpaan media massa tidak memiliki hubungan yang signifikan dengan sikap petani terhadap Program GLIP Berbasis Padi.

\section{Saran}

Berdasarkan hasil penelitian mengenai sikap petani terhadap Program Gelar Lapang Inovasi Pertanian (GLIP) Berbasis Padi di Kecamatan Guluk-Guluk, Kabupaten Sumenep, dapat diajukan saran sebagai berikut:

Balai Pengkajian Teknologi Pertanian (BPTP) Jawa Timur yang terkait dengan Program Gelar Lapang Inovasi Pertanian (GLIP) Berbasis Padi diharapkan lebih memfasilitasi persebaran informasi di media massa, baik cetak, eletronik, maupun internet. Sehingga petani lebih mudah untuk mengakses informasi terkait program.

Pengalaman pribadi para petani sebaiknya lebih ditingkatkan dengan mengikuti kegiatan yang berkaitan dengan Program GLIP Berbasis Padi.
Diharapkan petani akan mampu dan lebih terbiasa mengatasi permasalahan yang ada dengan mengikuti kegiatan penyuluhan dan pelatihan yang berisikan pemecahan masalah yang terkait dengan usaha taninya.

Hendaknya budaya terkait keterbukaan terhadap inovasi dari dalam maupun luar desa semakin ditingkatkan, selain untuk menambah pengalaman petani, hal inijuga dapat meningkatkan hasil usahataninya.

Hendaknya peran penyuluh lebih ditingkatkan lagi, sehingga petani dapat lebih banyak mendapatkan saran dan masukan terkait usahatani untuk kedepannya, sehingga petani dapat lebih berkembang.

\section{DAFTAR PUSTAKA}

Arifin, Bustanul. 2010. Strategi Baru Pembangunan Pertanian. http://tkpkri.org/. Diakses pada tanggal 19 Maret 2017.

Azwar, Saifuddin. 2013. Sikap Manusia Teori dan Pengukurannya Edisi ke 2. Yogyakarta: Pustaka Pelajar Offset.

Drakel A. 2008. Analisis usaha tani terhadap masyarakat kehutanan di DusunGumi, Desa Akelamo, Kota Tidore Kepulauan. Jurnal AGRIKAN. Vol. 1(1).

KEMENTAN. 2015. Rencana Strategis Direktorat Jendral Tanaman Pangan Tahun 2015-2019. Jakarta: Direktorat Jendral Tanaman Pangan.

Koesno, Tini Siniati, 2016. Peningkatan Komunikasi, Koordinasi Dan Diseminasi Inovasi Pertanian Di Provinsi Jawa Timur. Rencana Diseminasi Hasil Pengkajian (RDHP) Tahun 2016. Malang: Balai Pengkajian Teknologi Pertanian Jawa Timur.

Mahmud, M. Dimyati. 2009. Psikologi Pendidikan. Yogyakarta: BPFE.

Mardikanto, Totok. 1993. Penyuluhan Pembangunan Pertanian. Surakarta: UNS Press. 
Rodjak, A. 2006. Manajemen Usahatani Jilid II. Bandung: Pustaka Gratuna

Sugiyono. 2012. Metode Penelitian Kuantitatif Kualitatif dan R\&D. Bandung : Alfabeta.

Suhardiyono, L. 1992. Penyuluhan : Petunjuk bagi Penyuluh Pertanian. Jakarta: Erlangga.

Walgito, Bimo. 1990. Psikologi Sosial. Yogyakarta: Andi Offset. 